\section{A brief history of punctoplasty: the 3-snip revisited}

\begin{abstract}
Purpose To determine when and how to perform punctoplasty, review the history, and determine the efficacy of posterior ampullectomy.

Method Retrospective analysis of 53 cases of punctal stenosis, operated by a single surgeon by means of posterior ampullectomy via 3snips. A review of the history of the procedure from papers found with a Medline search for 1-snip, 2-snip, 3-snip, and punctoplasty.

Results In all, 102 sets of notes were reviewed. The age range was from 9 to 89 years with a mean age of 56 years. A total of $74 \%$ of patients were female. We excluded 22 patients who had additional surgery and 16 patients who elected not to have surgery. There was no comment as to success or failure in four sets of notes and seven notes could not be found; these cases were also excluded. Of the remaining 53 patients, success was documented in 49 cases, or $92 \%$. Conclusions The historical review helps explain the debate about the procedure. The retrospective review confirms that posterior ampullectomy via 3-snips is an effective procedure.

Eye (2005) 19, 16-18. doi:10.1038/sj.eye.6701415

Published online 30 April 2004
\end{abstract}

Correspondence: RH Caesar Cheltenham General

Hospital

Sandford Road

Cheltenham

Gloucestershire, UK

Tel: + 447973318271

Fax: + 448454222585

E-mail: riccaesar@

hotmail.com

Received: 19 May 2003 Accepted: 29 December 2003

Published online: 30 April 2004

The authors have no proprietary interest in the paper
RH Caesar and AA McNab

Despite this long list it remains an uncommon condition. The anatomy of the punctum, ampulla, and canaliculus is consistent and straightforward. The surgery involved in attempting to resolve the stenosis is now commonly described as a 1-, 2-, or 3-snip procedure.

As these descriptions would imply the exact number of cuts required to perform the procedure, it is not surprising that there remains, especially among general ophthalmologists, debate about how best to perform the surgery, and therefore uncertainty as to whether the operation is effective or not. The historical review explains these procedures.

\section{History}

In 1853, Bowman ${ }^{1}$ presented a 1-snip procedure, supported in 1873 by Arlit. ${ }^{2}$ The procedure involved an incision of the entire length of the canaliculus with a canaliculus knife. This had the significant disadvantage of destroying the capillary action of the canaliculus. In 1926, Graves $^{3}$ described his posterior ampullectomy, refined into the modern 3-snip by Thomas in $1951^{4}$ and Viers in $1955 .^{5}$ In 1962, Jones ${ }^{6}$ repopularised the 1-snip with a single vertical snip down the ampulla. The obvious problem was failure through re-approximation of the adjacent raw cut ends of the ampulla. In recognition of this, Jones suggested punctal dilatation if the punctum was starting to reclose and eventual 2-snip procedure if needed (the first snip down the ampulla and the second along the canaliculus from the lower edge of the first). As an alternative to 3 -snips, Hughes and Maris in 1967 used a punch to perform the ampullectomy, ${ }^{7}$ revisited in 1991 and 1992 by Edelstein and Reiss. ${ }^{8}$ Undeterred, the proponents of 1-snip suggested increased success by preventing the reunion of the cut ends. Dolin and Hecht ${ }^{9}$ in 1986 suggested placing the lid under tension with a 4:0 suture passed through the tarsus and anchored 
laterally over sterile buttons. In 1993, Lam and Tessler ${ }^{10}$ went further, suggesting the use of mitomycin $\mathrm{C}$ as adjunctive therapy in iatrogenic punctal stenosis. Perhaps sensing a trend to make a simple procedure more complex, in 1993 Offutt and Cowen ${ }^{11}$ suggested an altogether new microsurgical approach to punctoplasty involving excision of the stenotic puncta followed by microscopic externalisation of the vertical canaliculus.

We present a retrospective review of 3-snip punctoplasty. All cases were performed by a single surgeon (AAM), and consisted of a posterior ampullectomy by means of three snips.

\section{Methods}

The patient notes were pulled from the surgical database by searching for punctal stenosis in the diagnosis and/or punctoplasty in the surgery.

The surgery involved $\frac{1}{2} \mathrm{ml}$ of $2 \%$ lignocaine with $1: 100000$ epinephrine injected subcutaneously below the lower punctum. The punctum would be found with a punctum seeker and dilated sufficiently to allow the posterior wall of the ampulla to be grasped with toothed microforceps. The microforceps then should maintain their grip on the posterior wall throughout the procedure. Vannas scissors are then used to excise the posterior wall of the ampulla with three snips, the first two downwards on each side of the forceps and the third across the bottom. Chloramphenicol ointment was applied to the lower conjunctival fornix four times each day, and the patient was reviewed after 1 week.

Success was defined as a subjective improvement in symptoms.

\section{Results}

In all, 102 sets of notes were reviewed. The age range was from 9 to 89 years with a mean of 56 years. A total of $74 \%$ of patients were female. Of the initial 102 sets of notes, 49 had to be excluded. The reason for exclusion included 22 patients who had additional surgery, 16 patients who elected not to have surgery, no comment as to success or failure in four sets of notes, and seven notes that could not be found. Of the remaining 53 eligible patients, success, measured as a subjective improvement in epiphora, was documented in 49 cases, or $92 \%$. These subjective results were documented either at postoperative clinic review, or by postoperative telephone call. The patients were discharged after this postoperative review.

\section{Discussion}

Punctoplasty is one of the most straightforward surgical procedures. There has, however, remained debate as to how best to perform the procedure, and whether the procedure is effective. There is also no commonly agreed definition of what constitutes punctal stenosis. We used the simple clinical test of whether or not the undilated punctum would admit a $26 \mathrm{~g}$ lacrimal cannula. If the punctum would not admit the cannula without prior dilatation, it was classified as stenosed. The indication for punctoplasty is a patient with both epiphora and a stenosed punctum, patent to syringing once the punctum is dilated.

With respect to the surgery, the instructional nomenclature of 1-, 2-, and 3-snip has not helped the debate. The anatomical principle of punctoplasty is to enlarge permanently a stenosed punctum, bring the enlarged punctum closer to the tear meniscus, and preserve the canaliculus. By basic surgical principles, it is clear that the posterior wall of the ampulla needs to be excised to achieve these aims. By using three-snips, the raw edges are not in contact and should not immediately heal and re-stenose the punctum. As surgeons, we are always searching for improvements, and ideally simplification in all our surgical techniques. Historically, it would appear that the concept of an effective '1-snip' procedure was too attractive to ignore. The failure of 1snip then led to more complicated surgery in trying to prevent re-approximation of the adjacent raw cut ends of the ampulla. In her 2001 text on lacrimal surgery, Olver ${ }^{12}$ comments on the 1-snip 'it is not an elegant procedure'.

This paper is limited by being a retrospective review of a single technique. We cannot therefore give any evidence to prove that 3-snip is more effective than 1- or 2-snip. While we accept these limitations, we would like to propose posterior ampullectomy by either three-snips or one punch as the most anatomically and surgically logical procedure for effective punctoplasty. It is simple, quick, and in this series improved function in $92 \%$ of patients.

\section{References}

1 Bowman W. Methode de traitement applicable a l'epiphora dependent du renversement en dehors ou de l'obliteration des points lacrymaux. Ann Oculist 1853; 29: 52-55.

2 Arlit F. Operationen an den Thranenwegen. In: Graefe A, Saemisch T (eds). Handbuch der Gesammten Augenheilkunde. Verlag Von Wilhelm Englemann: Leipzig, East Germany, 1874, pp 479-480.

3 Graves B. Making a new lacrimal punctum. Am J Ophthalmol 1926; 9: 675-677.

4 Thomas JBT. A modification of Graves' operation for epiphora due to stenosis of the lacrimal punctum. $\mathrm{Br} J$ Ophthalmol 1951; 35: 306. 
5 Viers ER. Disorders of the canaliculus. In: The Lacrimal System. Grune \& Stratton: New York, 1955, pp 46-47.

6 Jones LT. The cure of epiphora due to canalicular disorders, trauma and surgical failures on the lacrimal passages. Trans Am Acad Ophthalmol Otolaryngol 1962; 66: 506-524.

7 Hughes WL, Maris CSG. A clip procedure for stenosis and eversion of the lacrimal punctum. Trans Am Acad Ophthalmol Otolaryngol 1967; 71: 653-655.

8 Edelstein J, Reiss G. The wedge punctoplasty for treatment of punctal stenosis. Ophthalmic Surg 1992; 23(12): 818-821.
9 Dolin SL, Hecht SD. The punctum pucker procedure for stenosis of the lacrimal punctum. Arch Ophthalmol 1986; 104(7): 1086-1087.

10 Lam S, Tessler HH. Mitomycin as adjunct therapy in correcting iatrogenic punctal stenosis. Ophthalmic Surg 1993; 24(2): 123-124.

11 Offutt IV WN, Cowen DE. Stenotic puncta: microsurgical punctoplasty. Ophthal Plast Reconstr Surg 1993; 9(3): 201-205.

12 Olver J. Localised punctal and proximal canalicular problems. In: Colour Atlas of Lacrimal Surgery. Butterworth Heinemann: London, 2001, pp 146. 